\title{
Diagnostic Implementation of Fast and Selective Integrin-Mediated Adhesion of Cancer Cells on Functionalized Zeolite L Monolayers
}

Arianna Greco, ${ }^{\S, 1}$ Laura Maggini,${ }^{\S, 2}$ Luisa De Cola,${ }^{* 2}$ Rossella De Marco, ${ }^{1}$ Luca Gentilucci ${ }^{*}, 1$

${ }^{1}$ Department of Chemistry “G. Ciamician”, University of Bologna, via Selmi 2, 40126 Bologna, Italy.

${ }^{2}$ Institut de science et d'ingénierie supramoléculaires (ISIS), Université de Strasbourg, 8 Allée Gaspard Monge, 67000 Strasbourg, France and Institut für Nanotechnologie (INT), Karlsruhe Institute of Technology (KIT) - Campus Nord, Hermann-von-Helmholtz-Platz 1, 76344 Eggenstein-Leopoldshafen, Germany.

*L.G. Phone: +39 0512099570; fax: +39 0512099456; e-mail: luca.gentilucci@unibo.it

* L.De C. Phone: +39 0512099570; fax: +39 0512099456; e-mail: decola@unistra.fr

\section{Contents}

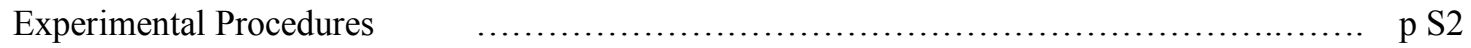

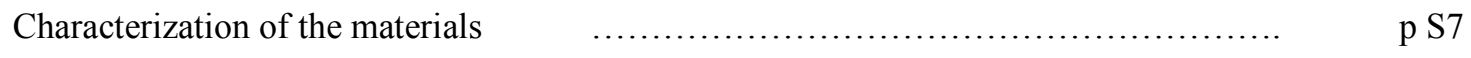

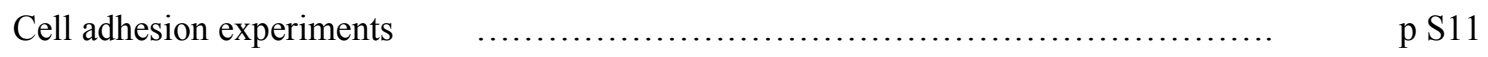




\section{Experimental Procedures}

Materials and Methods. Standard chemicals, including protected amino acids, were purchased from commercial sources and used without further purification. Flash chromatography was performed on silica gel (230-400 mesh), using mixtures of distilled solvents. The purity of $c$ [RGDfK] and its synthetic precursors was assessed by analytical RP-HPLC performed with an Agilent 1100 series apparatus, using a RP column [Phenomenex mod. Gemini $3 \mu \mathrm{C} 18$ 110A 100x3.0 mm (P/No 00D-4439-Y0)]; column description: stationary phase octadecyl carbon chain bonded silica (C18) with TMS end capping, fully porous organosilica solid support, particle size $3 \mathrm{~mm}$, pore size $110 \AA$, length $100 \mathrm{~mm}$, internal diameter $3 \mathrm{~mm}$; DAD $210 \mathrm{~nm}$; mobile phase: from 9:1 $\mathrm{H}_{2} \mathrm{O} / \mathrm{CH}_{3} \mathrm{CN}$ to $2: 8 \mathrm{H}_{2} \mathrm{O} / \mathrm{CH}_{3} \mathrm{CN}$ with the addition of $0.1 \%$ TFA, in $20 \mathrm{~min}$ at a flow rate of $1.0 \mathrm{~mL} / \mathrm{min}$, followed by $10 \mathrm{~min}$ at the same composition. Semi-preparative RPHPLC was performed with an Agilent 1100 series apparatus, using a RP column [ZORBAX mod. Eclipse XDBC18 PrepHT cartridge 21.2 x $150 \mathrm{~mm} 7 \mu$ (P/No 977150-102)]; column description: stationary phase octadecyl carbon chain bonded silica (C18), double end capped, particle size $7 \mu \mathrm{m}$, pore size $80 \AA$, length $150 \mathrm{~mm}$, internal diameter $21.2 \mathrm{~mm}$; DAD $210 \mathrm{~nm}$; mobile phase from 8:2 $\mathrm{H}_{2} \mathrm{O} / \mathrm{CH}_{3} \mathrm{CN}$ to $100 \% \mathrm{CH}_{3} \mathrm{CN}$ with the addition of $0.1 \% \mathrm{TFA}$, in $10 \mathrm{~min}$ at a flow rate of $12 \mathrm{~mL} / \mathrm{min}$. MS (ESI) analysis was performed using a MS single quadrupole HP 1100 MSD detector, with a drying gas flow of $12.5 \mathrm{~L} / \mathrm{min}$, nebulizer pressure 30 psgi, drying gas temp. $350{ }^{\circ} \mathrm{C}$, capillary voltage $4500(+)$ and $4000(-)$, scan 50-2600 amu. The synthetic procedures by MW irradiation were performed with a microwave oven (Micro-SYNTH Microwave Labstation for Synthesis) equipped with a built-in ATC-FO advanced fiber optic automatic temperature control. ${ }^{1} \mathrm{H}$ NMR spectrum of c[RGDfK] was recorded with a Varian Gemini apparatus at $400 \mathrm{MHz}$ in a 5 $\mathrm{mm}$ tube, using $0.01 \mathrm{M}$ peptide at RT.

Zeolites were prepared according to a standard procedure previously reported in the literature. ${ }^{\mathrm{S} 1,2}$ 3isocyanatepropyltriethoxysilane, 3-aminopropyltriethoxysilane, TEA, DMF, Toluene, PFA, DiO, DiD, DiL, DXP were purchased from Sigma Aldrich. PDMS was obtained from Dow Corning corporation (184 silicon elastomer base, SYLGARD). Glass plates $(\theta 1.2 \mathrm{~cm})$ used for zeolite monolayers were purchased from Servoprax GmbH. Dulbecco's modified culture medium (DMEM), FBS, penicillin, glutamine, trypsin and PBS solution ( $\mathrm{pH}$ 7.2) were purchased from Gibco (Life Technologies). HeLa cells and Glioma C6 were obtained from ATCC/LGC Standards GmbH (Wesel, Germany) and cultivated according to the provider's protocol. T-293 cells were kindly provided by Dr. Eric Robinet at the IHU, Hopital Civil Strasbourg. XPS analyses were performed using a K-Alpha ${ }^{\mathrm{TM}}+$ X-ray Photoelectron Spectrometer (XPS) System (Thermo Scientific). Monochromatic Al K alpha X-rays were used (15 keV, $72 \mathrm{~W}, 200 \mu \mathrm{m}$ spot diameter). Spectra were measured using a pass energy of $200 \mathrm{eV}$ for survey spectra and $50 \mathrm{eV}$ for core level spectra. The analyzed zeolite samples were prepared by drop-casting an ethanolic dispersion $(0.1 \mathrm{mg} / \mathrm{mL})$ of the particles onto a glass coverslip pre-coated with $\mathrm{Au}$ (Emitech $\mathrm{K} 575 \mathrm{X}$ peltier cooled) for $3 \mathrm{~min}$ at $60 \mathrm{~mA}$. The monolayers were analyzed as they were, without further treatment. TGA analyses were conducted on a TGA 1 STAR System Mettler Toledo machine under nitrogen atmosphere. The samples $(0.1-2 \mathrm{mg})$ were kept at 
$50{ }^{\circ} \mathrm{C}$ for 30 minutes for stabilization, then heated from 50 to $750{ }^{\circ} \mathrm{C}$ at a speed of $10{ }^{\circ} \mathrm{C} / \mathrm{min}$, and held at this temperature for further 30 minutes before cooling. The analyses were performed under a gas flow of $\mathrm{N}_{2}$ at $50 \mathrm{~mL} / \mathrm{min}$. SEM images were recorded with a FEI Quanta FEG 250 instrument (FEI corporate, Hillsboro, Oregon, USA) at an operating distance of $10 \mathrm{~mm}$ and with an acceleration voltage of $5 \mathrm{kV}$. The zeolite samples were prepared by drop-casting a dispersion of particles in EtOH onto a glass cover slip, subsequently sputter coated with $\mathrm{Au}$ (Emitech $\mathrm{K} 575 \mathrm{X}$ peltier cooled) for $60 \mathrm{~s}$ at $60 \mathrm{~mA}$ prior to fixation on an Al support. SAMs monolayers were analyzed without further manipulation. Powder X-ray diffraction (PXRD) measurements were performed on a Bruker D2 PHASER diffractometer using a $\mathrm{Cu}$ Ka-radiation $(1.54184 \AA)$ and a Ni K $\beta$-filter at $300 \mathrm{~W}(30 \mathrm{kV}, 10 \mathrm{~mA})$ power with a LYNXEYE scintillation detector. Samples were mounted on a zero background silicon sample holder. The measurement was performed from a $2 \theta$ value from 5 to $45^{\circ}$ with exposure time of 1.5 second per step. All measurements were performed at room pressure and RT. Confocal images were obtained with a Zeiss LSM 710 microscope system, 63X magnification, numerical aperture 1.3 of Zeiss LCI Plan-NEOFLUAR water immersion objective lens (Zeiss $\mathrm{GmbH})$. All image processing was performed with the ZEN 2011 software.

Synthesis of $\mathrm{H}$-Asp $(\mathrm{OtBu})-\mathrm{D}-\mathrm{Phe}-\mathrm{Lys}(\mathrm{Boc})-\mathrm{Arg}(\mathrm{Mtr})-\mathrm{Gly}-\mathrm{OH}{ }^{\mathrm{S} 3}$ The linear pentapeptide precursor of $\mathrm{c}[\mathrm{RGDfK}]$ was assembled on the commercially-available Gly-preloaded 2-chlorotrityl resin (Gly loading 1.1 $\mathrm{mmol} / \mathrm{g}$ resins $)$. The resin $(0.5 \mathrm{~g})$ was swollen in 1:2 DMF/dimehylpirrolidone $(5 \mathrm{~mL})$ for $30 \mathrm{~min}$ before use. Fmoc-amino acid ( 3 equiv), the coupling reagents TBTU ( 3 equiv), HOBt ( 3 equiv), DIPEA ( 6 equiv), were added to the resin and the mixture was reacted for 10 min under $\mathrm{MW}$ irradiation $\left(50 \mathrm{~W}, 50{ }^{\circ} \mathrm{C}\right)$. The resin was washed 3 times with DMF $(5 \mathrm{~mL})$ and $\mathrm{MeOH}(5 \mathrm{~mL})$. Deprotection of Fmoc group was carried out by treatment of $20 \%$ piperidine/DMF for 3 min under MW irradiation $\left(50 \mathrm{~W}, 50{ }^{\circ} \mathrm{C}\right)$. After that, the resin was washed 3 times with DMF $(5 \mathrm{~mL})$ and $\mathrm{MeOH}(5 \mathrm{~mL})$. The resulted peptidyl resin was treated with AcOH and TFE in $\mathrm{CH}_{2} \mathrm{Cl}_{2}(1: 1: 4 \mathrm{v} / \mathrm{v} / \mathrm{v}, 15 \mathrm{~mL})$ for $90 \mathrm{~min}$ at RT. The solution of the cleaved cyclic peptide was concentrated at reduced pressure. The residue was lyophilized to afford $0.32 \mathrm{~g}$ of crude peptide. The purity of the product was determined $85 \%$ by reversed-phase (RP) HPLC (see General Methods); Rt $=6.55$ min. MS (ESI) $m / z:[\mathrm{M}+\mathrm{H}]^{+}$calcd for $\mathrm{C}_{46} \mathrm{H}_{71} \mathrm{~N}_{9} \mathrm{O}_{13} \mathrm{~S}, 990.5$; found, 990.8 .

Synthesis of c[Asp(OtBu)-D-Phe-Lys(Boc)-Arg(Mtr)-Gly]. The linear peptide $(0.32 \mathrm{~g}$, circa $0.32 \mathrm{mmol})$ in DMF $(10 \mathrm{~mL})$ was added dropwise at RT using a temporized syringe in $12 \mathrm{~h}$, to a stirred solution of HATU ( 3 equiv) and DIPEA (6 equiv) in DMF (40 mL). The reaction mixture was stirred for other $12 \mathrm{~h}$. The solvent was evaporated at reduced pressure, the residue diluted with water $(5 \mathrm{~mL})$ was extracted 3 times with EtOAc $(15 \mathrm{~mL})$. The residue was purified by flash chromatography over silica gel (eluent: $100 \%$ EtOAc) giving the cyclopeptide (205 mg, $66 \%$ ), 90\% pure by RP-HPLC (general Methods). Rt $=9.69 \mathrm{~min}$. MS (ESI) $m / z:[\mathrm{M}+\mathrm{H}]^{+}$calcd for $\mathrm{C}_{46} \mathrm{H}_{69} \mathrm{~N}_{9} \mathrm{O}_{12} \mathrm{~S}$, 972.5; found, 972.8 .

Procedure for the final deprotection to $c[R G D f K]$. The fully-protected cyclopeptide $(0.2 \mathrm{~g} \mathrm{mg}, 0.20 \mathrm{mmol})$ was dissolved in TFA-TIS- $\mathrm{H}_{2} \mathrm{O}(95: 2.5: 2.5 \mathrm{v} / \mathrm{v} / \mathrm{v}, 20 \mathrm{~mL})$ and the solution was stirred at RT for $2 \mathrm{~h}$. The solution was concentrated at reduced pressure and the residue was lyophilized to afford the crude peptide. 
The product c[RGDfK] was isolated by semi-preparative RP-HPLC (General Methods) as a TFA salt (121 $\mathrm{mg}, 85 \%$ ), $>95 \%$ pure as determined by analytical RP-HPLC, see General Methods; Rt $=1.00 \mathrm{~min}$. MS (ESI) $m / z$ : $[\mathrm{M}+\mathrm{H}]^{+}$calcd for $\mathrm{C}_{27} \mathrm{H}_{41} \mathrm{~N}_{9} \mathrm{O}_{7}, 604.3$; found, 604.5. ${ }^{1} \mathrm{H}$ NMR was found to match with the literature $^{\mathrm{S} 4,5}\left(400 \mathrm{MHz}, \mathrm{D}_{2} \mathrm{O}, \delta\right): 0.67-0.73(\mathrm{~m}, 2 \mathrm{H}, \mathrm{LysH} \gamma), 1.27-1.56(\mathrm{~m}, 7 \mathrm{H}, \mathrm{LysH} \beta, \mathrm{LysH} \delta, \operatorname{ArgH} \gamma$, $\operatorname{ArgH} \beta), 1.73(\mathrm{~m}, 1 \mathrm{H}, \operatorname{ArgH} \beta), 2.40$ (dd, J=7.2, $15.6 \mathrm{~Hz}, 1 \mathrm{H}, \operatorname{AspH} \beta), 2.51$ (dd, J=6.9, $15.6 \mathrm{~Hz}, 1 \mathrm{H}$, AspH $)$ ), 2.69-2.73 (m, 2H, LysHz), 2.80 (m, 1H, PheH $\beta$ ), 2.95 (dd, J = 5.2, 13.2 Hz, 1H, PheH $\beta$ ), 3.050-3.09

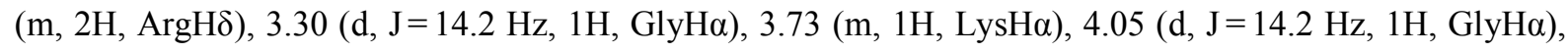

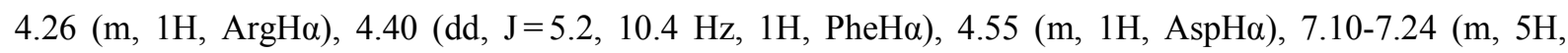
PheArH).

Zeolite loading with DXP 170 dye (Zeo-DXP). Zeolites ${ }^{\mathrm{S} 1,2}(300 \mathrm{mg})$ and DXP $(6.23 \mathrm{mg})$ were kept overnight under high vacuum. The solid mixture was then introduced in a sealed flask and heated in a rotary furnace at $300{ }^{\circ} \mathrm{C}$ for $48 \mathrm{~h}$. The flask was then opened and the powder washed and centrifuged (30 min, $40 \mathrm{krcf}$ ) in butan-1-ol until the supernatant ceased UV emission. The material was characterized by means of XPS, TGA, and SEM.

Functionalization of Zeo-DXP with 3-Isocyanopropyltriethoxysilane (IC-Zeo-DXP). Zeo-DXP (50 mg) were suspended in a $50 \mathrm{~mL}$ flask containing a mixture of toluene $(5 \mathrm{~mL})$ and TEA $(0.2 \mathrm{~mL})$, and sonicated for 15 min until the precipitate was dissolved. Then 3 -(triethoxysilyl)propyl isocyanate $(0.8 \mathrm{~mL})$ was added, and the mixture further sonicated for $3 \mathrm{~h}$. The suspension was then cooled to RT and centrifuged for $20 \mathrm{~min}$ at 40 krcf. The precipitate was then redispersed by sonication in toluene and centrifuged three times to remove unreacted silane. The material was characterized by means of XPS, TGA, and SEM.

Preparation of IC-Zeo-DXP SAMs. Glass plates were introduced into a $100 \mathrm{~mL}$ flask and activated with 3:1 $\mathrm{H}_{2} \mathrm{SO}_{4} / \mathrm{H}_{2} \mathrm{O}_{2}(10 \mathrm{~mL})$ at $100{ }^{\circ} \mathrm{C}$ for $1 \mathrm{~h}$. The solution was removed and the plates were washed with bidistilled water $(3 \times 30 \mathrm{~mL})$ followed by ethanol $(3 \times 20 \mathrm{~mL})$ and finally dried under nitrogen flow. The plates were then fixed onto a Teflon support to avoid any surface overlap and the system was placed into a $100 \mathrm{~mL}$ round bottom flask containing toluene $(30 \mathrm{~mL})$. APTES $(0.8 \mathrm{~mL})$ and TEA $(0.2 \mathrm{~mL})$ were added and the flask was heated at $115^{\circ} \mathrm{C}$ overnight. Subsequently, the plates were removed from the solution and washed with toluene $(5 \mathrm{~mL})$ and ethanol $(5 \mathrm{~mL})$ and dried with nitrogen flow. The plates were then placed into a suspension of isocyanate-functionalized zeolites in toluene $(1 \mathrm{mg} / \mathrm{mL}, 2 \mathrm{~mL})$, and sonicated for 30 minutes, before recovering the plates, rinsing them with toluene $(5 \mathrm{~mL})$ and air-drying them before use. The SAM was characterized by means of SEM.

Preparation of the PDMS elastomeric stamp and patterning of IC-Zeo-DXP SAMs. The monomeric silicon elastomer and the activator agent were introduced in a plastic test tube $(10: 1 \mathrm{w} / \mathrm{w})$. The components were mixed and the mixture was spilled into a Petri dish containing three patterned Si wafers $(50 \mu \mathrm{m} \times 50 \mu \mathrm{m}$, width $\times$ depth). The viscous liquid on Petri dish was degassed at reduced pressure, then heated at $50{ }^{\circ} \mathrm{C}$ for 3 h. Finally, the polymer was cut around the negative stamp, the latter was removed, and the resulting elastomeric stamp employed for the soft lithography of the SAMs. The elastomeric stamp was pressed onto the monolayer for $30 \mathrm{sec}$. Effective patterning was analyzed by SEM. 
Functionalization of IC-Zeo-DXP SAMs with c [RGDfK]. c[RGDfK] $(1 \mathrm{mg})$ and TEA $(10 \mu \mathrm{L})$ were dissolved in DMF (1 mL). The solution was sonicated for $5 \mathrm{~min}$ to favor the complete dissolution of the peptide. A plate of patterned monolayer composed of DXP-loaded zeolite NPs was immersed in the solution and heated at $35{ }^{\circ} \mathrm{C}$ for $3 \mathrm{~h}$. Finally, the plate was removed from the solution and washed with DMF $(5 \mathrm{~mL})$ and EtOH $(5 \mathrm{~mL})$, then air dried. The SAM was characterized by means of XPS, and SEM.

Functionalization of $c[R G D f K]-S A M s$ with rhodamine $B$ isothyocyanate isomer $I$. A c[RGDfK]functionalized SAMs was immersed in a solution of rhodamine B isothiocyanate in EtOH $(10 \mathrm{mg} / \mathrm{mL})$ at RT for $30 \mathrm{~min}$. Finally the plate was removed from the solution and washed in $\mathrm{EtOH}(5 \mathrm{~mL})$ and air dried. The SAM was characterized by means of XPS, and confocal microscope.

\section{Biological methods}

Cell culture. Cells were cultured in a media composed as follows: $88 \%$ Dulbecco's Modified Eagle Medium (DMEM), 10\% Fetal Bovine Serum, 1\% Penicillin-Streptomycin and 1\% L-Glutamine $200 \mathrm{nM}$. The cell culture was performed under $5 \% \mathrm{CO}_{2}$, and at $37{ }^{\circ} \mathrm{C}$. Detachment of the cells from the culture flask was performed by trypsination. Cell counting was performed with a CASY ${ }^{\circledR}$ cell counter and analyzer machine (System Model TT, Roche Diagnostics).

Cell staining. Cells $\left(1 \times 10^{6} / \mathrm{mL}\right)$ were suspended in a serum-free culture medium, and the dye $(5 \mu \mathrm{L} / \mathrm{mL})$ was added. Glioma C6 and HeLa cells were stained with $\mathrm{DiO}$ while T-293 cells were stained with DiD. The suspension was then gently mixed and incubated for $10-20$ minutes at $37^{\circ} \mathrm{C}$, before being centrifuged at $1500 \mathrm{rpm}$ for $5 \mathrm{~min}$. The supernatant was finally removed, and the cells gently resuspended in fresh medium at $37^{\circ} \mathrm{C}$. The washes were repeated twice.

Cell adhesion and counting. The monolayers were washed with PBS solution to remove all the impurities. The printed DXP SAMs, either naked or functionalized with the peptide, were placed in a 24 well plate (diameter $4 \mathrm{~cm})$ and seeded with cells $\left(1 \times 10^{5} \mathrm{HeLa}\right.$, Glioma C6, or T-293 cells). Each plate was covered with the culture medium $(2 \mathrm{~mL})$ and incubated for $30 \mathrm{~min}$. Then the culture medium was removed, the plates washed twice with PBS $(5 \mathrm{~mL})$ and fixed with PFA $(3 \mathrm{~mL})$. After 10 minutes, PFA was removed, and the plates were washed twice with bi-distilled water $(5 \mathrm{~mL})$ and mounted on microscopy glass for confocal microscope analysis. The cells counting is an average of three values each referred to a surface of 0.0025 $\mathrm{cm}^{2}$. This averaged value is then normalized to the total area of the monolayer, $1 \mathrm{~cm}^{2}$. 
i)

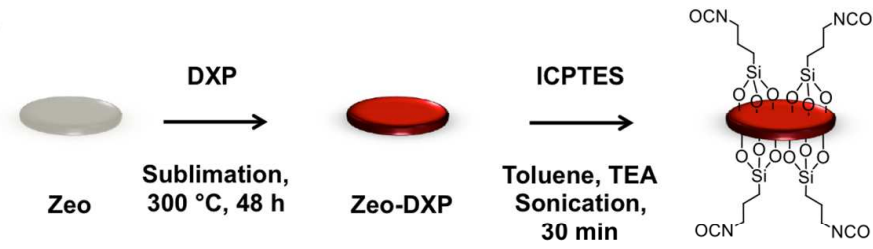

ii)
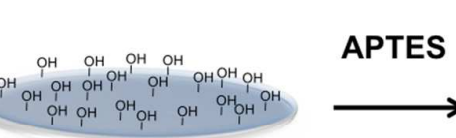

Toluene, TEA

$115^{\circ} \mathrm{C}$, o.n.

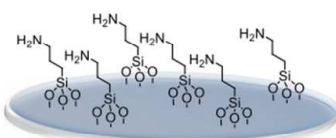

Toluene, TEA

Sonication, $\mathbf{3 0} \mathrm{min}$
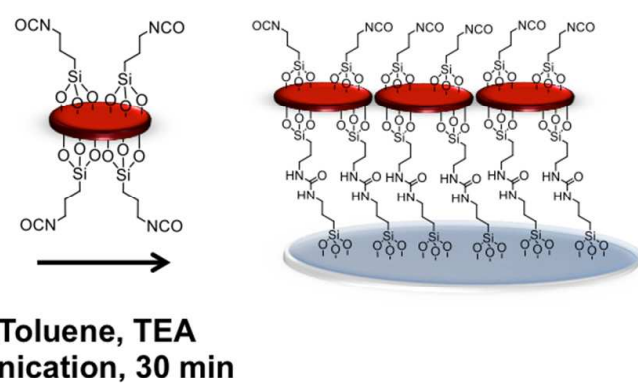

II
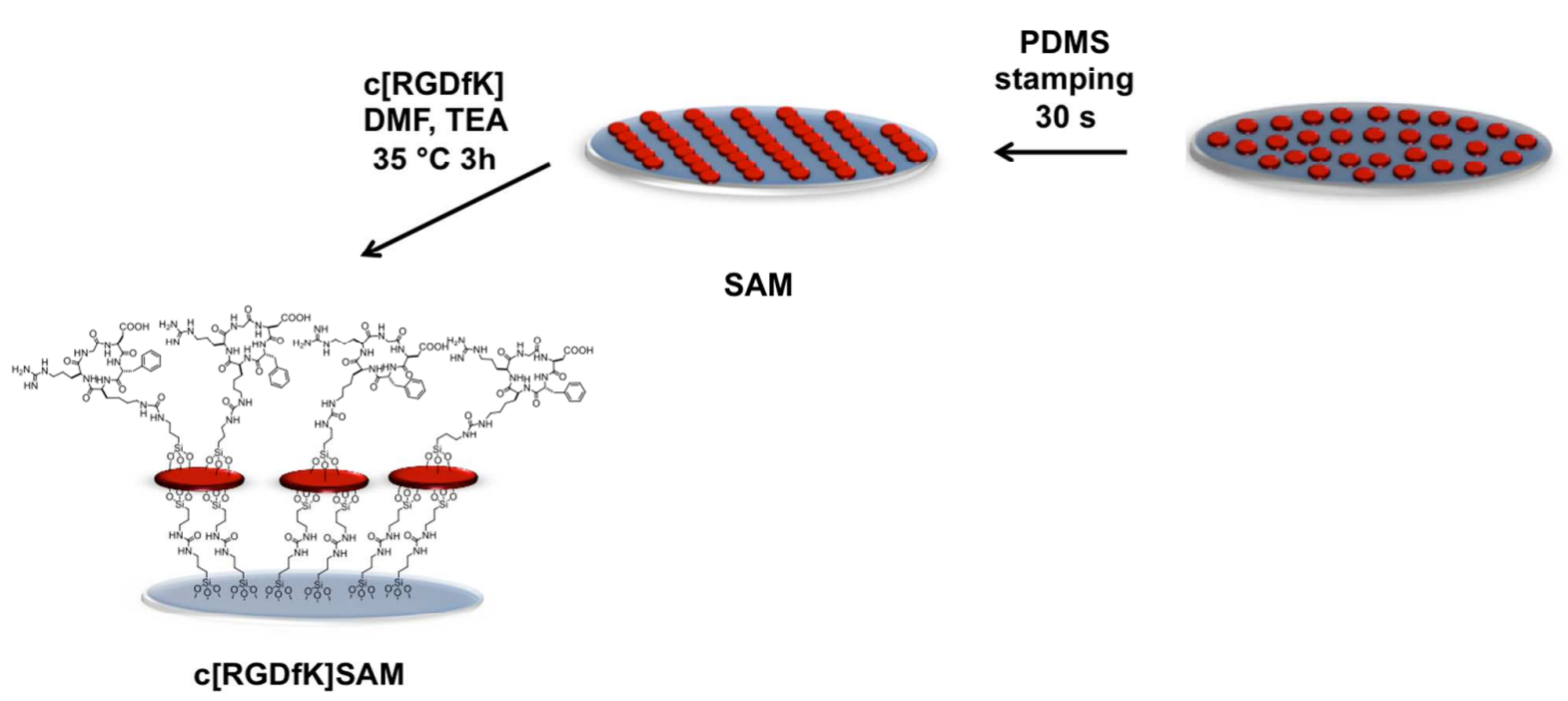

= glass substrate
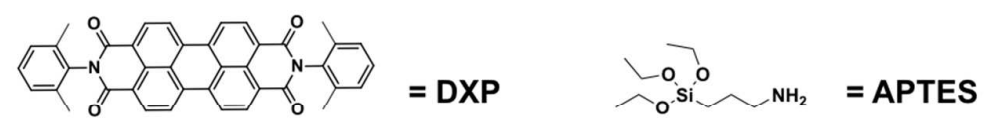

= Zeolite
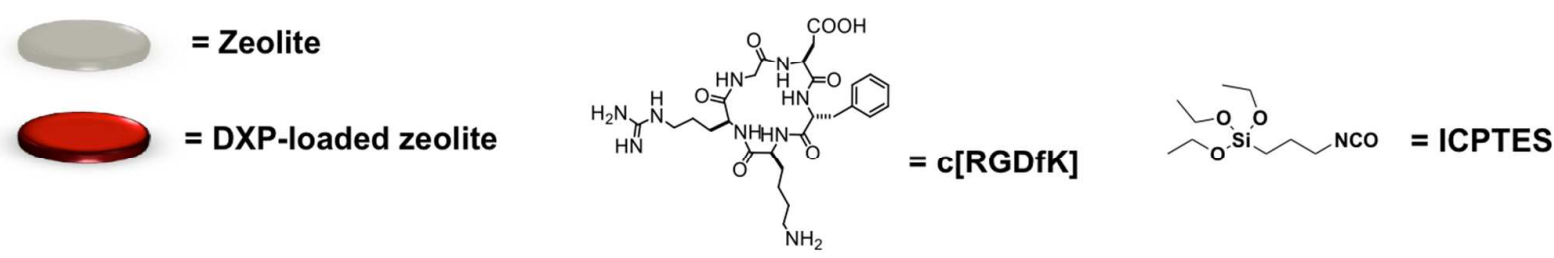

Figure S1. Preparation of DXP-loaded c[RGDfK]-functionalized patterned SAMs of zeolite L crystals: i) synthesis of IC-Zeo-DXP used for the monolayer preparation; ii) c[RGDfK]-SAM preparation. 


\section{Characterization of the materials}
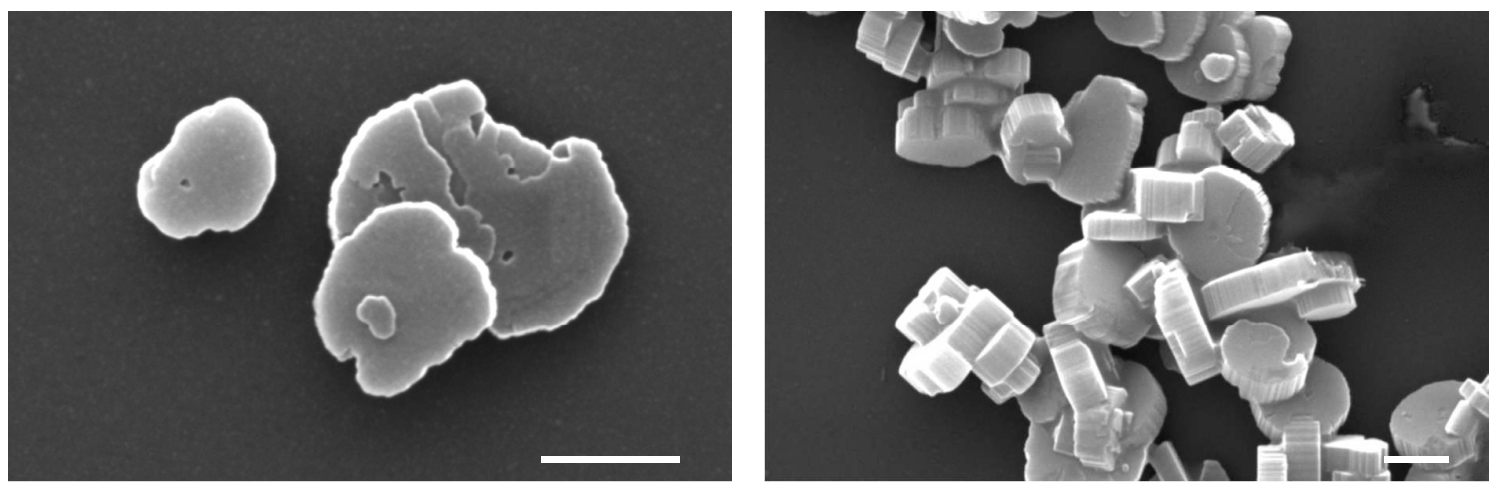

Figure S2. SEM image of disk-shaped zeolite L crystals; scale bar $=500 \mathrm{~nm}$.

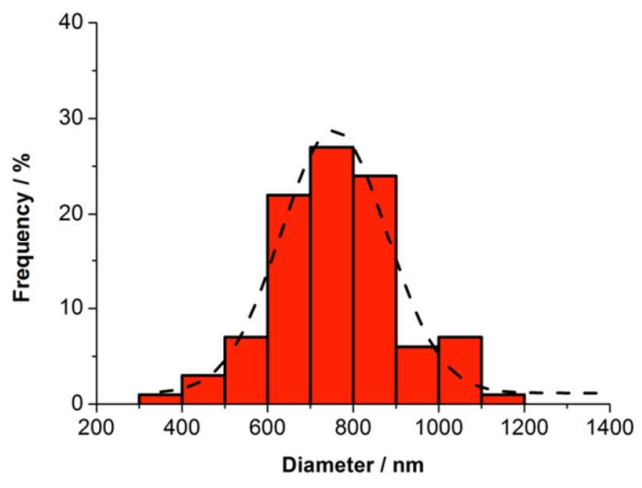

Figure S3. Size distribution diagram of disk-shaped zeolite L (derived from SEM images).

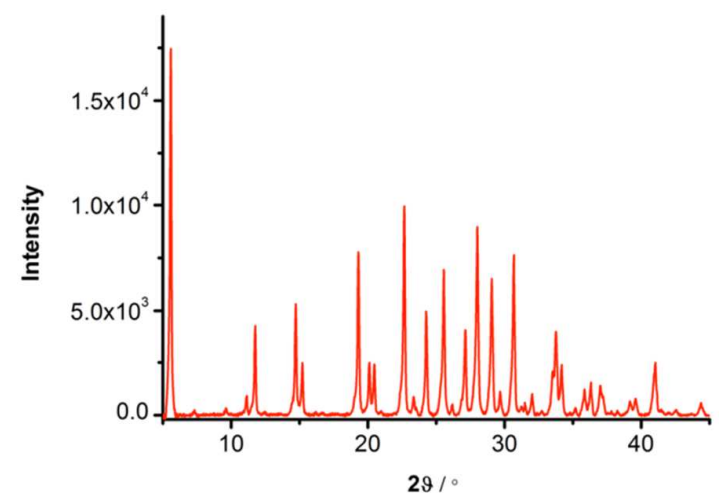

Figure S4. Powder XRD diffraction pattern of zeolite L. 
Zeo

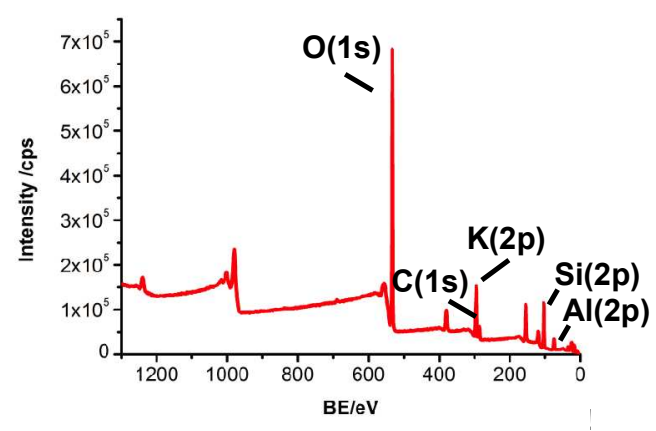

IC-Zeo-DXP

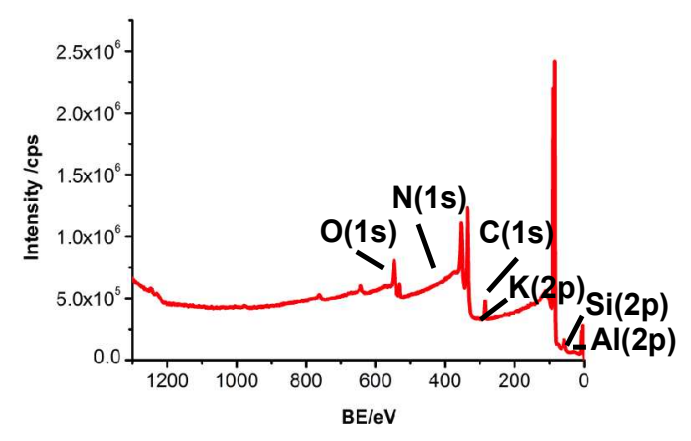

c[RGDfK]-SAM

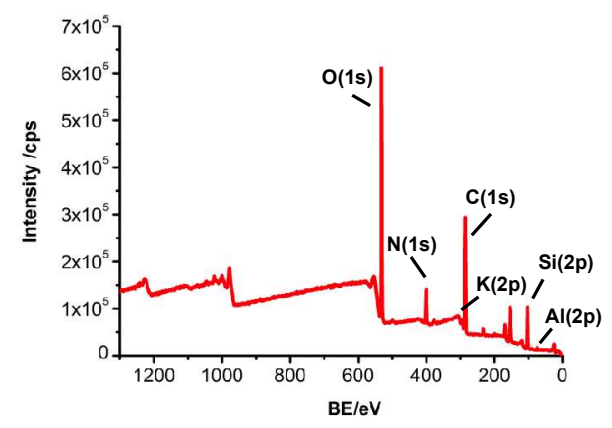

\section{Zeo-DXP}

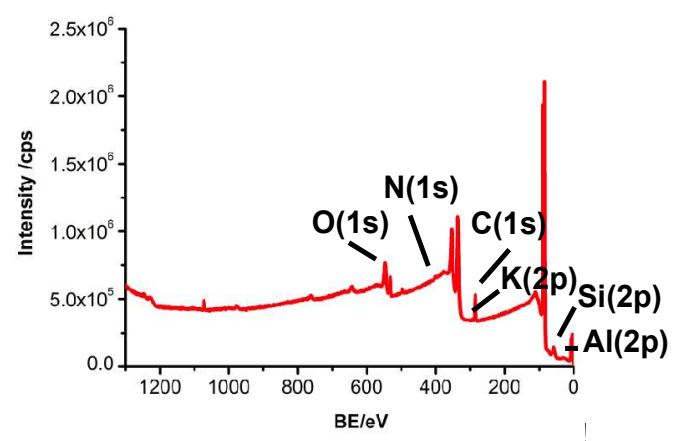

IC-SAM

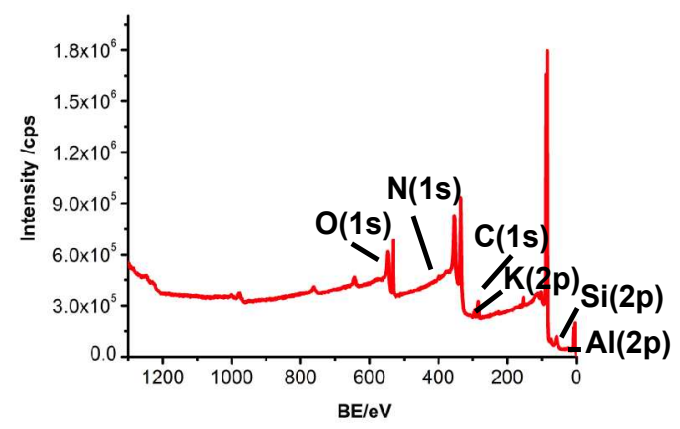

N(1s) comparison

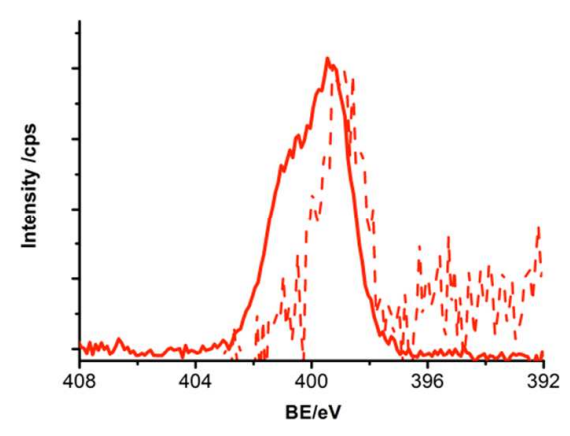

Figure S5. XPS survey spectra for the pristine, the derivatized, and the monolayers of zeolite L materials, and comparison of the high resolution XPS analysis of N(1s) of the IC-SAM (dashed line) and c[RGDfK]-SAM (full line) samples. 
Table S1. XPS analysis results for the pristine, the derivatized and the monolayers of zeolite L materials.*

\begin{tabular}{lcccccc}
\hline & $\mathrm{Si}(2 \mathrm{p})^{* *}$ & $\mathrm{Al}(2 \mathrm{p})^{* *}$ & $\mathrm{O}(1 \mathrm{~s})^{* *}$ & $\mathrm{~K}(2 \mathrm{p})^{* *}$ & $\mathrm{C}(1 \mathrm{~s})^{* *}$ & $\mathrm{~N}(1 \mathrm{~s})^{* *}$ \\
\hline Zeo & $21.4 \pm 0.1$ & $6.9 \pm 0.8$ & $58.4 \pm 0.7$ & $6.5 \pm 1.0$ & $6.1 \pm 1.0$ & $0.7 \pm 0.2$ \\
Zeo-DXP & $18.9 \pm 2.5$ & $8.7 \pm 3.3$ & $44.0 \pm 5.8$ & $5.6 \pm 0.7$ & $20.7 \pm 3.7$ & $2.0 \pm 0.1$ \\
IC-Zeo-DXP & $16.0 \pm 2.3$ & $12.7 \pm 1.6$ & $29.3 \pm 3.6$ & $3.5 \pm 1.2$ & $33.0 \pm 6.7$ & $5.5 \pm 0.8$ \\
IC-SAM & $17.5 \pm 3.1$ & $7.5 \pm 0.9$ & $37.2 \pm 0.1$ & $2.1 \pm 1.2$ & $30.6 \pm 2.9$ & $5.1 \pm 2.8$ \\
c[RGDfK]-SAM & $14.2 \pm 2.1$ & $1.5 \pm 0.7$ & $32.8 \pm 3.1$ & $0.2 \pm 0.2$ & $42.6 \pm 4.7$ & $8.7 \pm 1.2$ \\
\hline
\end{tabular}

* Data not to be considered quantitative. **Atomic \%.

a)

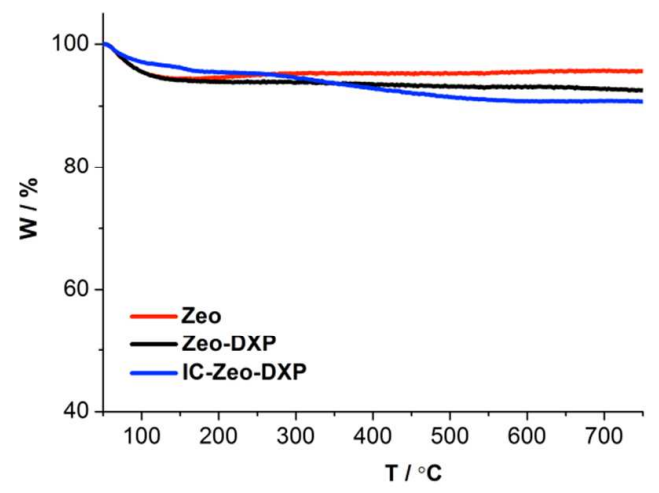

b)

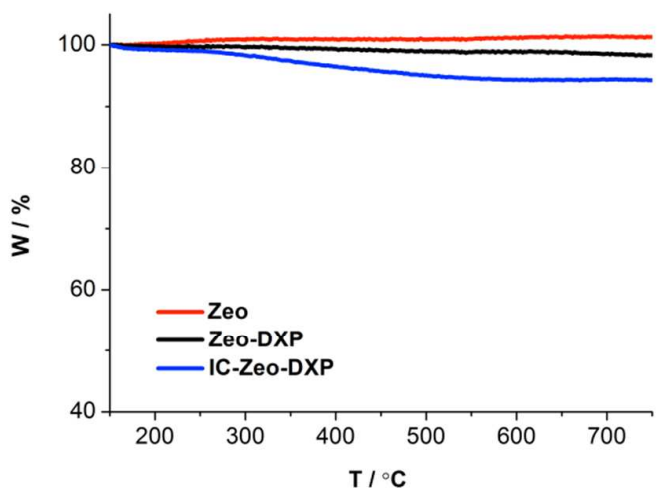

Figure S6. a) TGA analysis of the pristine and the derivatized zeolite L materials; b) normalization of the TGA curves after removing the contribution of the water present in the zeolite materials (pristine zeolites used as reference). 


\section{Zeo-DXP}
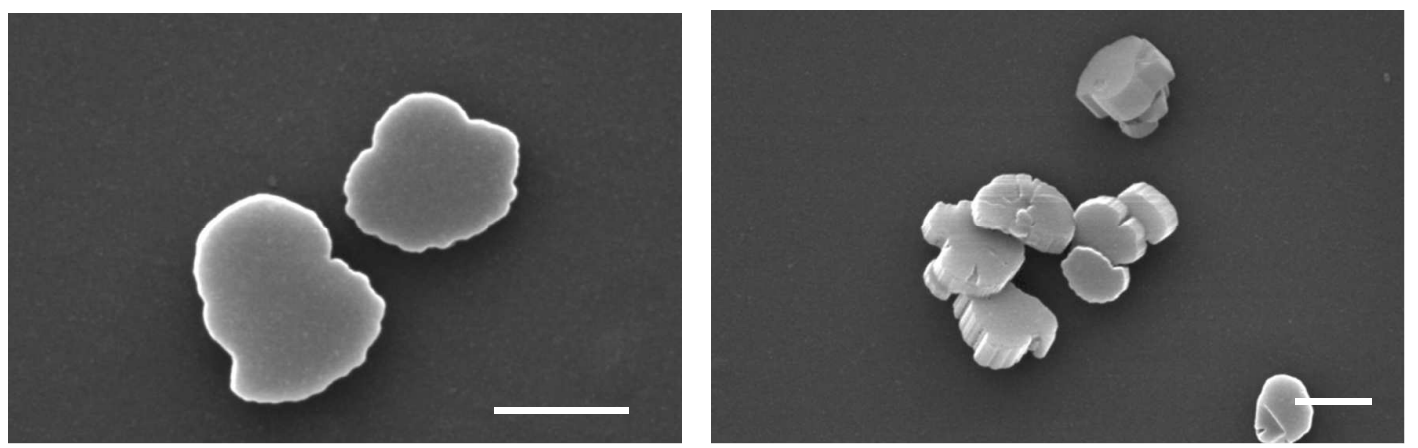

\section{IC-Zeo-DXP}
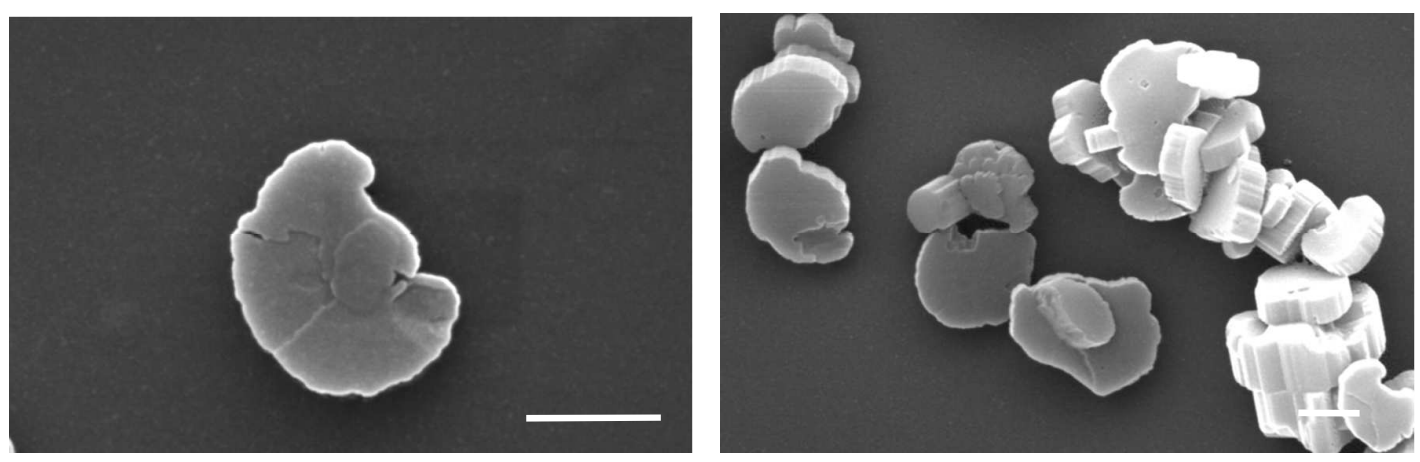

Figure S7. SEM images of the functionalized particles: Zeo-DXP and IC-Zeo-DXP. Scale bar $=500 \mathrm{~nm}$. 


\section{Cell adhesion experiments}
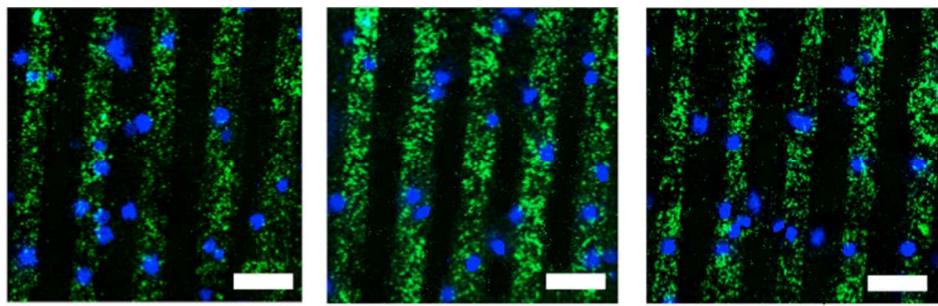

a)
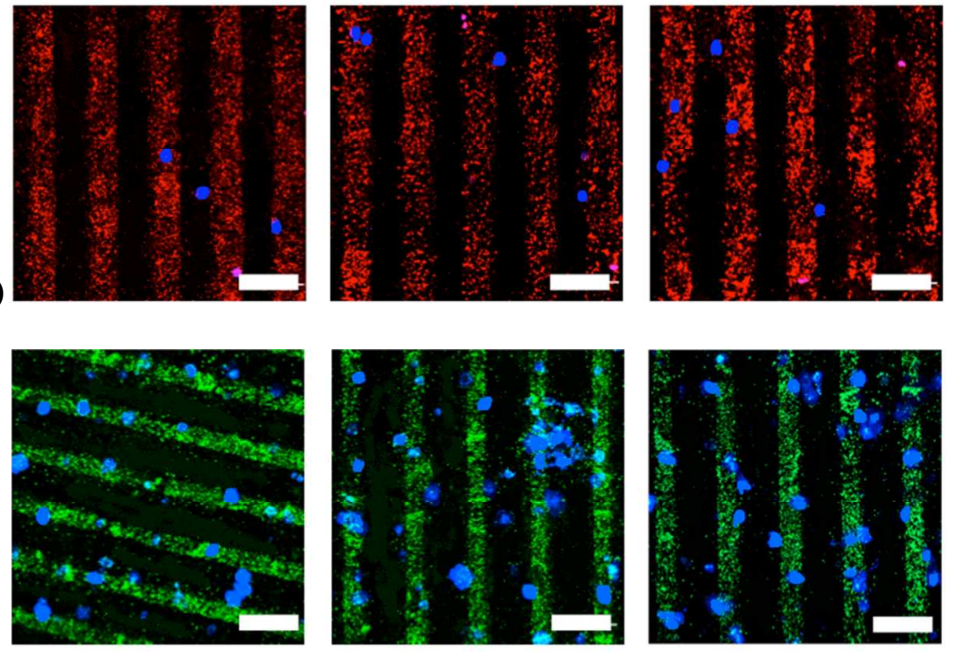

b)
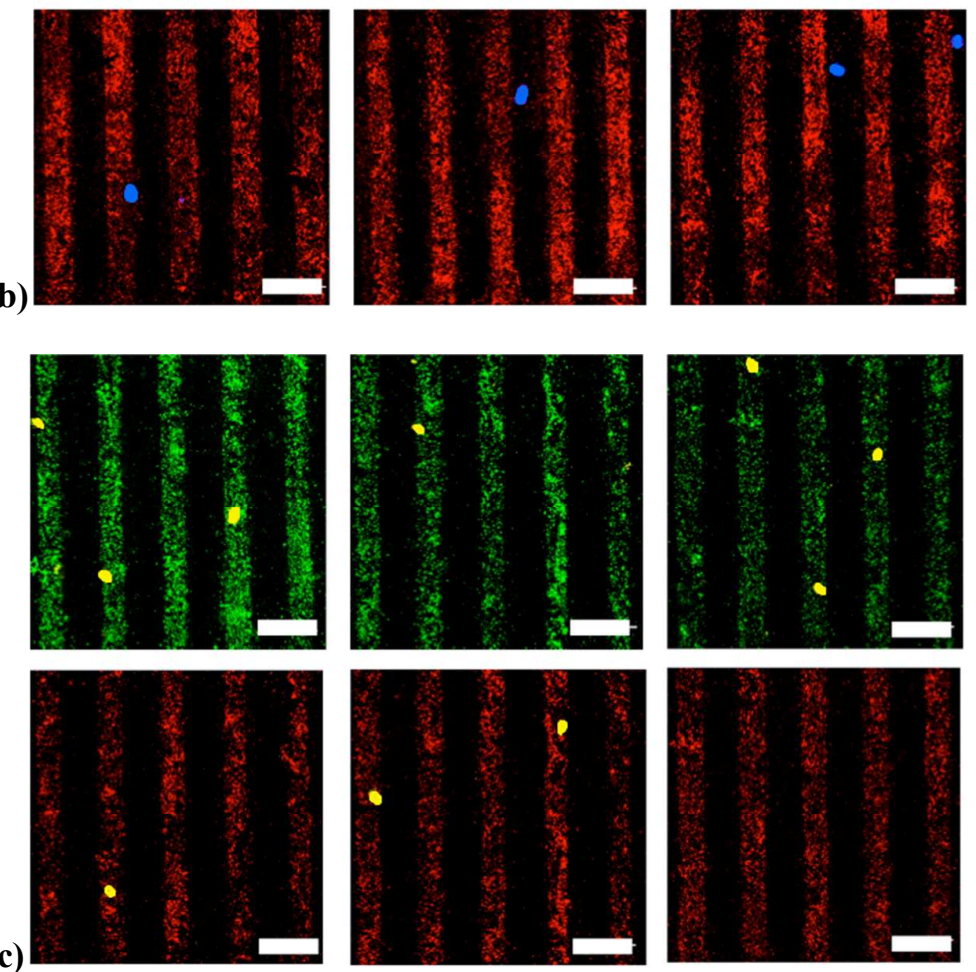

Figure S8. Representative confocal microscopy images for the adhesion experiments of HeLa (a), Glioma C6 (b) and T-293 cells (c) on isocyanate-functionalized SAMs (in red; DXP $\lambda_{\text {exc }}=490 \mathrm{~nm}$ ) and c[RGDfK]-functionalized SAMs (in green; DXP $\lambda_{\text {exc }}=490 \mathrm{~nm}$ ): HeLa and Glioma C6 cells are visualized in blue (DiO staining, $\lambda_{\text {exc }}=484 \mathrm{~nm}$ ); T-293 in yellow (DiD staining, $\lambda_{\text {exc }}=644 \mathrm{~nm}$ ). Scale bar $=100 \mu \mathrm{M}$. 
Table S2. Cell counting analysis for the single population adhesion experiments.*

\begin{tabular}{l|l|l|l}
\hline Surface & HeLa & Glioma C6 & T-293 \\
\hline IC-SAM $^{* *}$ & $3.2 \pm 1.1$ & $0.8 \pm 0.4$ & $0.1 \pm 0.05$ \\
c[RGDfK]-SAM ${ }^{* *}$ & $11.4 \pm 0.8$ & $15.3 \pm 0.5$ & $0.2 \pm 0.05$ \\
ratio cells on c[RGDfK]-SAM/IC-SAM** & 3.5 & 19.1 & 2 \\
\hline
\end{tabular}

* Total area monitored $=0.0025 \mathrm{~cm}^{2}$; cell count values normalized to an area of $1 \mathrm{~cm}^{2}$

$* * \mathrm{x} 10^{3}$
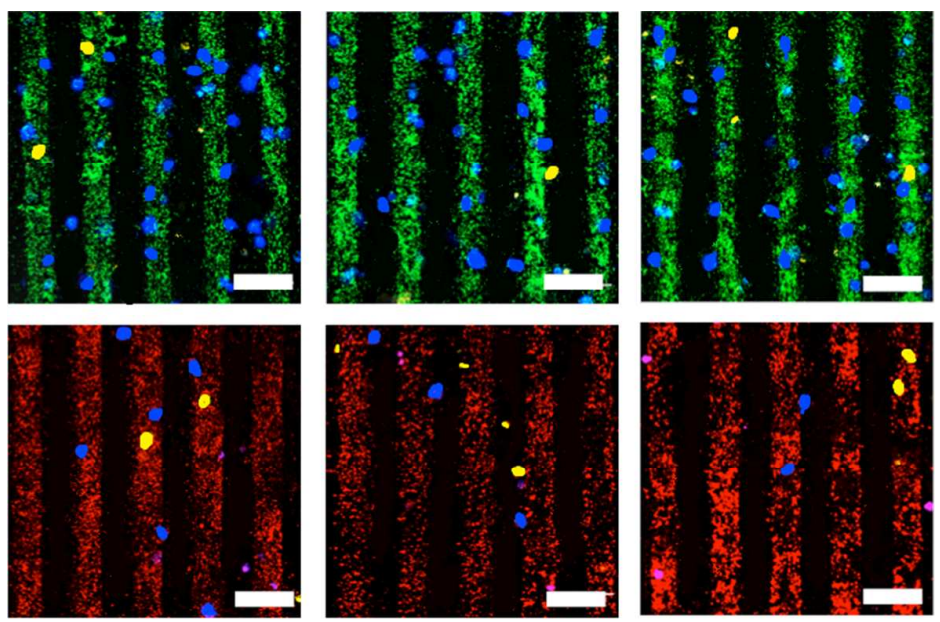

Figure S9. Representative confocal microscopy images for the adhesion experiment of HeLa and T-293 cells (DiO and DiD staining, respectively; $\mathrm{DiO} \lambda_{\text {exc }}=484 \mathrm{~nm}$; DiD $\lambda_{\text {exc }}=644 \mathrm{~nm}$ ) on c[RGDfK]-functionalized SAMs (top) or on isocyanate-functionalized (bottom): HeLa cells are visualized in blue; T-293 in yellow. Scale bar $=50 \mu \mathrm{M}$.
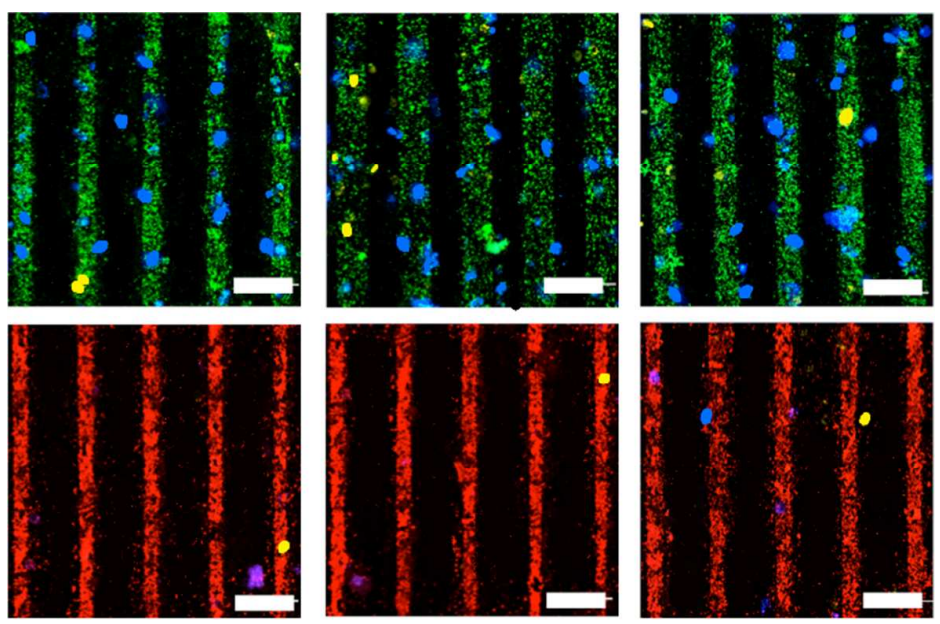

Figure S10. Confocal microscopy image for the adhesion experiment of Glioma C6 and T-293 cells (DiO and DiD staining, respectively; DiO $\lambda_{\text {exc }}=484 \mathrm{~nm}$; DiD $\lambda_{\text {exc }}=644 \mathrm{~nm}$ ) onto c [RGDfK]-functionalized SAMs (top) or isocyanatefunctionalized SAMs (bottom): Glioma C6 cells are visualized in blue; T-293 in yellow. Scale bar $=50 \mu \mathrm{M}$. 
Table S3. Cell counting analysis for the mixed population adhesion experiments.

\begin{tabular}{l|ll|ll}
\hline Surface & \multicolumn{2}{|l|}{ HeLa/ T-293 } & \multicolumn{2}{l}{ Glioma C6/T293 } \\
\hline & HeLa & T-293 & Glioma C6 & T-293 \\
\cline { 2 - 4 } IC-SAM** & $3.6 \pm 0.4$ & $0.8 \pm 0.1$ & $2.5 \pm 0.3$ & $0.8 \pm 0.1$ \\
c[RGDfK]-SAM** & $19.7 \pm 2.2$ & $2.3 \pm 0.5$ & $20.7 \pm 6.6$ & $1.0 \pm 0.2$ \\
cancer/primary cells on c[RGDfK]-SAM & 8.5 & 20.7 & \\
& & & \\
$*$ Total area monitored $=0.0025 \mathrm{~cm}^{2} ;$ cell count values normalized to an area of $1 \mathrm{~cm}^{2}$ \\
$* * \times 10^{3}$
\end{tabular}

\section{References}

(S1) Devaux, A., Calzaferri, G., Miletto, I., Cao, P., Belser, P., Brühwiler, D., Khorev, O., Häner, R., Kunzmann, A. (2013) Self-absorption and luminescence quantum yields of dye-zeolite L composites $J$. Phys. Chem. C 117, 23034-23047.

(S2) Zabala Ruiz, A., Li, H., Calzaferri, G. (2006) Organizing supramolecular functional dye-zeolite crystals. Angew. Chem. Int Ed. 45, 5282-5287.

(S3) Yamada, K., Nagashima, I., Hachisu, M., Matsuo, I., Shimizu, H. (2012) Efficient solid-phase synthesis of cyclic RGD peptides under controlled microwave heating. Tetrahedron Lett. 53, 1066-1070.

(S4) Haubner, R., Finsinger, D., Kessler, H. (1997) Stereoisomeric peptide libraries and peptidomimetics for designing selective inhibitors of the $\alpha v \beta 3$ integrin for a new cancer therapy. Angew. Chem. Int. Ed. Engl. 36, 1374-1389.

(S5) Kantlehner, M., Finsinger, D., Meyer, J., Schaffner, P., Jonczyk, A., Diefenbach, B, Nies, B., Kessler, H. (1999) Selective RGD-Mediated adhesion of osteoblasts at surfaces of implants. Angew. Chem, Int. Ed. $38,560-562$. 